\title{
OSTEOARTHRITIS INCREASES THE RISK OF CARDIOVASCULAR DISEASE: DATA FROM THE OSTEOARTHRITIS INITIATIVE
}

Nicola Veronese $e^{\mathrm{a}, \mathrm{b}}$, Brendon Stubbs ${ }^{\mathrm{c}, \mathrm{d}}$, Marco Solmi ${ }^{\mathrm{b}, \mathrm{e,f}}$, Toby O Smith ${ }^{\mathrm{g}}$, Jean-Yves Reginster ${ }^{\mathrm{h}, \mathrm{i}}$, Stefania Maggi ${ }^{\mathrm{a}}$

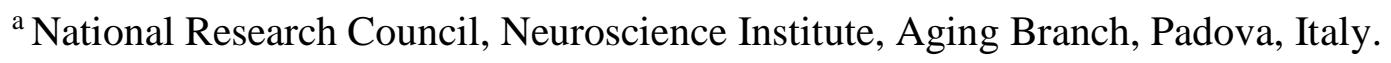

${ }^{\mathrm{b}}$ Institute for clinical Research and Education in Medicine (IREM), Padova, Italy

c Physiotherapy Department, South London and Maudsley NHS FoundationTrust, Denmark Hill, London SE5 8AZ, United Kingdom.

${ }^{\mathrm{d}}$ Health Service and Population Research Department, Institute of Psychiatry, King's College London, De Crespigny Park, London SE5 8 AF, United Kingdom.

${ }^{\mathrm{e}}$ Department of Neurosciences, University of Padova, Padova, Italy.

${ }^{\mathrm{f}}$ National Health Care System, Padua Local Unit ULSS 17, Italy.

${ }^{\mathrm{g}}$ Faculty of Medicine and Health Sciences, University of East Anglia, Norwich Research Park, Norwich, NR4 7TJ, United Kingdom.

${ }^{\mathrm{h}}$ Department of Public Health, Epidemiology and Health Economics, University of Liège, CHU of Liège, Bât. B23, Quartier Hôpital, Avenue Hippocrate, 13, 4000, Liège, Belgium.

${ }^{\mathrm{i}}$ Methodology Support Unit in Epidemiology and Biostatistics, University of Liège, Liège, Belgium.

\section{Corresponding Author:}


Nicola Veronese, MD

National Research Council, Neuroscience Institute, Aging Branch, Padova, Italy.

Via Giustiniani, 2 - 35128 Padova, Italy

Phone: +39 0498218492; Fax: +390498211218

Email: ilmannato@gmail.com 


\begin{abstract}
Objective: Although osteoarthritis (OA) is a common condition in older adults, the role of OA in increasing cardiovascular disease (CVD) incidence is still debated. The aim of this study was to investigate the association between OA and the onset of CVD in a large database of American adults. Design: Longitudinal.

Setting: Community-dwelling.

Participants: People with OA or at high risk of OA.

Measurements:. Osteoarthritis was defined as the presence of OA of the hand, knee, hip, back/neck or of other sites. CVD was defined as self-reported presence of heart attack, heart failure, stroke and other cerebral atherosclerotic conditions, and peripheral artery disease.

Results: A total 4,265 persons without CVD (mean age $=60.8$ years, females $=59.2 \%$ ) at baseline were analyzed (1,775 with OA versus 2,490 without). Over a mean of 8.2 years, according to an adjusted Cox's regression analysis for 11 potential baseline confounders, study participants with OA of any joint had a significantly higher risk of developing CVD compared to those without OA (Hazard ratio (HR): $=1.27 ; 95 \% \mathrm{CI}: 1.03-1.56)$. The presence of hand OA was associated with a higher risk of developing CVD (HR=1.31; 95\%CI: 1.01-1.68) with respect to those who had no OA. Knee, hip and back/neck OA did not, instead, increase the risk of developing CVD. The association between OA and CVD was significant in the women, but not in the men.
\end{abstract}

Conclusions: OA, in particular, when it affects the hand and is found in women, was associated with a higher risk of developing CVD.

Keywords: osteoarthritis; cardiovascular disease; epidemiology. 


\section{INTRODUCTION}

One of the most common causes of years lived with disability are chronic musculoskeletal disorders.[1] Osteoarthritis (OA) accounts for a considerable amount of this burden [2], with lower limb OA ranked the 11th highest contributor to global disability. [2]The prevalence of OA has been estimated as $10 \%$ in men and $20 \%$ in women over the age of 60 years having OA across the world. [3]

Increasing research is showing that OA might increase the risk of cardiovascular diseases (CVD) for several reasons. First, both OA and CVD share similar risk factors, namely low physical activity, hypertension, depression and obesity.[4-6] Secondly, compared to healthy controls, OA is often characterized by some degree of low-grade inflammation, another potential CVD risk factor.[7] Finally, the modifications of extra-cellular matrix, typical of OA[8], could further increase the risk of CVD.[9]

As summarized by a recent meta-analysis including 15 cross-sectional studies and more than 32 million of participants, there is a strong association between OA and CVD.[10] Individuals with OA were almost three times as likely to have heart failure or coronary heart disease compared with matched non-osteoarthritis cohorts. [10] Conversely, the longitudinal studies are still limited and with contrasting results. Three studies[11-13] reported that the presence of OA significantly increased the onset of CVD, while another large cohort study reported no such significant association[14], particularly after adjusting for the presence of disability. However, these studies presented with some limitations most notably for limited adjustment for potential confounders. Finally, due to the different criteria adopted, it was difficult to ascertain whether only symptomatic or radiological OA predicted the onset of CVD. 
The purpose of this study was thus to determine whether: i) people with OA are at increased risk of incident CVD compared to people without OA; ii) exists any difference among sites usually affected by OA (hand, hip, knee, back/neck, other) could predict CVD onset; and iii) if any difference between self-reported and clinical/radiological OA in predicting CVD onset.

\section{METHODS}

\section{Data source and subjects}

All participants in this study were recruited as part of the ongoing, publicly and privately funded, multicenter, and longitudinal Osteoarthritis Initiative (OAI study) (http://www.oai.ucsf.edu/). Specific datasets used are those recorded during baseline and screening evaluations (November 2008) (V00) and those evaluating the participants until the last evaluation available (96 months; V10). Patients with a high risk of knee osteoarthritis were recruited from 4 clinical sites in the United States (Baltimore, Maryland; Pittsburgh, Pennsylvania; Pawtucket, Rhode Island; and Columbus, Ohio) between February 2004 and May 2006 and were eligible if they 1) had knee osteoarthritis and reported knee pain in a 30-d period in the past 12 mo or 2) were at high risk of developing knee osteoarthritis (e.g., overweight or obese, knee injury or operation, parents or siblings with total knee replacement, frequent knee-bending activities that increase risk, and hand or hip osteoarthritis). All of the participants provided written informed consent. The OAI study protocol was approved by the institutional review board of the OAI Coordinating Center, University of California at San Francisco.

\section{Exposure}

The diagnosis for OA in our analysis was self-reported for the most common sites usually affected by OA (knee, hip, hand, back/neck, and other joints) asking to participant if one doctor said that 
he/she suffers from OA during his/her life. A summary variable ascertained as the presence of at least one site affected by self-reported OA was then calculated.

Since for knee OA, radiological diagnosis was also ascertained, an additional analysis was undertaken assessing knee OA defined as a combination of the clinical reporting and assessment of pain and stiffness (i.e. pain, aching or stiffness in or around the knee on most days during the last year), and radiographical OA on the baseline fixed flexion radiograph based on the presence of tibiofemoral osteophytes (correspondent to Osteoarthritis Research Society International atlas grades 1-3, clinical center reading).

\section{Outcomes}

The main outcome of interest was the onset of CVD during the follow-up period. As for OA, CVD was recorded through self-reported information.

We defined the development of CVD as the presence of heart attack, heart failure, unclog or bypass arteries in legs, and stroke, cerebrovascular accident, blood clot in brain, or transient ischemic attack. The presence of CVD in the OAI was recorded, other than baseline, during the V3 (24 months), V6 (48 months) and V10 (96 months).

\section{Covariates}

A number of variables was identified from the OAI dataset to explore the relationship between OA and incident CVD. These included: (1) physical activity evaluated through the Physical Activity Scale for the Elderly, a validated scale for assessing physical activity level in the elderly.[15] The scale covers 12 different activities, such as walking, sports, and housework, and is scored from 0 to 400 
and more (no maximum score has been defined); (2) race was defined as "whites" vs. others; (3) smoking habits as "previous/current" vs. never; (4) educational level was categorized as "degree” vs. others; (5) yearly income as < and missing data vs. $\geq 50,000 \$$; (6) co-morbidities assessed through the modified Charlson comorbidity score, with higher scores indicating an increased severity of conditions[16]; and (7) body mass index (BMI) recorded by a trained nurse. Among the several medical conditions assessed through the Charlson co-morbidity score, we reported descriptively the prevalence of some common diseases that could influence the association between OA and CVD, namely diabetes and cancer. Hypertension was diagnosed through self-reported information or in case of systolic blood pressure $\geq 140$ and/or diastolic blood pressure $\geq 90 \mathrm{mmHg}$. Blood pressure in the OAI study was measured by a trained nurse following a standard approach.

\section{Statistical analyses}

For continuous variables, normal distributions were tested using the Kolmogorov-Smirnov test. The data are shown as means and standard deviations (SD) for quantitative measures, and frequency and percentages for all discrete variables by OA presence at baseline. P-values were calculated for continuous variables using the independent Student T-test and for categorical parameters the chisquare test by OA presence at baseline.

Multivariate Cox's regression models were conducted using as exposure the presence of OA and as outcome incident CVD at follow-up visits. People dead during follow-up period were censored. Time to event was calculated as time to first CVD event.

Factors which reached a statistical significance between participants with OA vs. those without or significantly associated with CVD at follow-up (taking a p-value $<0.05$ as statistically significant) 
were included. Multi-collinearity among covariates was assessed through variance inflaction factor, taking a cut-off of 2 as reason of exclusion, but no variable was excluded for this reason. The basic model was not adjusted for any confounders, while the fully adjusted model included baseline values of: age (as continuous); gender; race (whites vs. others); BMI (as continuous); education (degree vs. others); smoking habits (current and previous vs. others); yearly income (categorized as $\geq$ or < 50,000\$ and missing data); PASE score (as continuous); Charlson comorbidity index; presence of hypertension (yes vs. no); and use of analgesic drugs (yes vs. no). Data of Cox's regression analysis were reported as hazard ratios (HRs) with correspondent 95\% confidence intervals (CIs).

In secondary analyses, specific joints affected by OA (categorized as knee, hip, hand, back/neck, or other joints) and the presence of knee OA, defined through radiological and clinical criteria, were taken as exposure variables. Participants without any presence of OA were taken as reference also in these analyses.

To test the robustness of our analyses, sensitivity analyses were conducted evaluating the interaction between the presence of self-reported and radiological/clinical diagnosis of OA and selected factor (e.g. gender, race, education, smoking habits, yearly income and presence/absence of diseases at baseline) in predicting CVD at follow-up. Gender emerged as potential moderator of our analyses (for interaction $<0.001$ ). Through this data are presented also by gender.

All analyses were performed using the SPSS 21.0 for Windows (SPSS Inc., Chicago, Illinois). All statistical tests were two-tailed and statistical significance was assumed for a p-value $<0.05$.

\section{RESULTS}

\section{Study participants}


At baseline, among 4,796 potentially eligible individuals, we excluded 313 had already a CVD, 21 did not have any information regarding OA and 197 without data during follow-up evaluations, obtaining a final sample of 4,265 participants

\section{Baseline analyses}

Overall, 4,265 participants (1,740 Males; 2,525 Females) with a mean age of 60.8 \pm 9.1 (range: 45-79) years were eligible for inclusion in the current study. At baseline, 1,775 people with OA (41.6\%) were compared with 2,490 participants without OA.

The baseline characteristics of the OA and non-OA participants are summarized in the Table $\mathbf{1}$ in the sample as whole and divided by gender. Independently from gender, participants with OA were significantly older and used more frequently analgesic drugs than those without OA. In men, participants with OA were more frequently obese, smokers, diabetic than those without OA, whilst in women, participants with OA were more frequently whites, sedentary (as shown by lower PASE scores), more educated and with a higher presence of co-morbidities as shown by higher Charlon's score (Table 1).

\section{Association between baseline osteoarthritis and incident cardiovascular disease}

After a mean period of 8.2 years, 416 individuals (9.8\% of baseline population) (113 developed heart attack, 190 heart failure, 151 strokes or other cerebrovascular conditions, and 72 peripheral artery disease) developed a CVD event. The global incidence rate of CVD was 16 (95\% CI: 0-41) events for 1000 persons-year. 
As shown in Figure 1, the incidence of CVD was significantly higher in those having OA at baseline compared to those without (OA: 17; 95\% CI: 0-48 vs. no OA: 14; 95\% CI: 0-37/1000 events for 1000 persons-year; $\mathrm{p}<0.001)$.

Table 2 shows the Cox's regression analyses by OA presence and for OA specific site. Taking those without any presence of OA as reference and after adjusting for 11 potential baseline confounders, OA was associated with a significant higher risk of CVD ( $\mathrm{HR}=1.27 ; 95 \% \mathrm{CI}: 1.03-1.56, \mathrm{p}=0.02)$, particularly when OA affected hand $(\mathrm{HR}=1.31 ; 95 \% \mathrm{CI}: 1.01-1.68, \mathrm{p}=0.04)$. The association between any site $\mathrm{OA}$ and incident $\mathrm{CVD}$ remains significant in women $(\mathrm{HR}=1.50 ; 95 \% \mathrm{CI}: 1.13-2.00, \mathrm{p}=0.005)$, but not in men (Table 2). In women, OA affecting hip ( $\mathrm{HR}=1.51 ; 95 \% \mathrm{CI}: 1.00-2.27, \mathrm{p}=0.048)$ and hand $(\mathrm{HR}=1.65 ; 95 \% \mathrm{CI}: 1.21-2.24, \mathrm{p}=0.001)$ increased the risk of $\mathrm{CVD}$, whilst in men no site was at increased risk of developing CVD.

Knee OA defined through radiological and clinical presence, did not show any significant association with incident CVD in the sample as whole ( $\mathrm{HR}=0.94 ; 95 \% \mathrm{CI}: 0.76-1.15, \mathrm{p}=0.52)$, nor in men $(\mathrm{HR}=1.03$; 95\%CI: $0.76-1.34, \mathrm{p}=0.85)$ or in women $(\mathrm{HR}=0.85 ; 95 \% \mathrm{CI}: 0.64-1.14, \mathrm{p}=0.28)$. 


\section{DISCUSSION}

In this large prospective study, we have demonstrated that the presence of OA at the baseline significantly increased the risk of CVD during follow-up period of about $27 \%$. Among the sites investigated in our analysis only hand OA was associated with an increased risk of CVD in the whole sample whilst, in women, also hip OA increased the risk of CVD. The association of OA with CVD was significant only in women, suggesting important gender differences.

In this cohort, OA seemed to be quite a strong predictor of the onset of CVD at follow-up. Several mechanisms have been suggested to explain the association between OA and CVD.[17] Firstly, the conditions in common between $\mathrm{OA}$ and CVD, such as age, hypertension and obesity. Among these factors, the association between $\mathrm{OA}$ and hypertension is relevant. Previous research has in fact reported that, among all potential CVD risk factors, hypertension is the most common prevalent in people having OA for several reasons, including alterations of extra-cellular matrix typical of OA that could lead firstly to hypertension and finally to CVD. [7,9] Secondly, a greater use of antiinflammatory drugs by people with OA could contribute to the onset of CVD.[18] However, our analyses were adjusted for these potential confounders, suggesting that other pathways are probably involved. Thirdly, OA probably promotes the onset of other potential CVD risk factors during followup (e.g. physical inactivity, obesity, disability) that could contribute to the higher CVD risk in our association.[19] Finally, changes in extracellular matrix remodeling or an altered Wnt signaling transduction may play a role in the development of CVD in people with OA.[20]

Previous longitudinal studies on the possible association between OA and CVD produced not univocal results. Whilst Nueusch et al.[11] found that OA increased the risk of CVD mortality in agreement with other studies [21], Hoeven et al. found no significant association between OA of the hand, knee or hip and CVD in 4,868 people over 55 years of age.[14] This finding is probably due to 
the different criteria used to diagnose OA: Hoeven et al. [14] used a clinical-radiological diagnosis of OA, whilst we used a self-reported information regarding the presence of OA as primary analysis. As confirmed by our results, it is likely that only symptomatic, and not to radiographic OA, is associated with a higher CVD risk.

Among the sites investigated in the sample as whole, only OA affecting the hand emerged as possible risk factor for CVD. The topic if hand OA could increase the risk of CVD is again controversial. Some cross-sectional studies, in fact, have shown that hand OA is associated with a higher presence of CVD, also in pre-clinical forms. For example in a study involving 5,342 older participants, hand OA was associated with a significant higher presence of carotid plaques, coronary and aortic calcifications, particularly in women.[22] It is known that hand OA is linked to the menopause more strongly than other sites[23] and the subsequent decrease in circulating endogenous estrogens, a feature which has also been linked to an increase in CVD rate.[24] However, some longitudinal studies have shown that hand OA was not associated with higher risk of CVD onset. [12,25] Therefore, other studies are needed to disentangle this topic.

When we analyzed our data separately by gender, OA only emerged as a significant CVD risk factor only in women, in agreement with the literature regarding this topic.[26] Even if why the association between OA and CVD is significant only in women is unclear. One hypothesis is that women make more use of analgesic drugs for these conditions than men, because they are more sensitive to pain.[17] Since these drugs have an unfavorable CVD profile, it is likely that this factor may play a role. Another possible explanation could be extracellular matrix (ECM) remodeling after menopause since, before this period of life, women are at decreased CVD risk than men. It is known that ECM is altered in OA (particularly in the cartilage joints)[27], but this process probably involves also arteries and heart.[9] Since after menopause the alterations of ECM is more rapid in women than men due to the loss of estrogens [24], it may be that these changes make the onset of CVD more likely in 
women than in men. Third, other researches have proposed that other pathways are probably involved in this gender difference, e.g. tool-like receptors (TLRs) pathways are more altered in postmenopausal women than men[28], and play a part in both OA[29] and CVD. [28] Finally, we should acknowledge that men are less represented in the OAI than women and so a type II error for analyses regarding men is possible.

Our findings should be considered within the limitations of our study. First, as mentioned before, the diagnosis of OA was self-reported, except for knee OA. Second, also the diagnosis of CVD and the comorbidities was self-reported and this could create a bias. The lack of data regarding medications could introduce another bias: for example, we found a prevalence of hypertension of $20 \%$, whilst in people aging about 60 years it is estimated in about 50\%.[30] Similarly, some drugs commonly used in the elderly (e.g. duloxetine) that could increase the risk of hypertension were not used as potential confounders in our analyses. Third, we don't have any information regarding CVD mortality and other cardiovascular events, such as hospitalization for CVD, that our recent research has shown been associated with the presence of OA. ${ }^{[12]}$ Fifth, people with OA at the baseline had already a higher prevalence of several CVD risk factors that could increase the risk of incident CVD. Although we have adjusted our analyses for all these factors, a selection bias could be not excluded. Finally, we did not assess any inflammatory marker, although inflammation could be associated with higher CVD risk.[31] Nonetheless, allowing for these caveats, our study involves a large population and the follow-up period seems to be appropriate for our outcome of interest. Moreover, we adjusted our analyses for multiple important confounders, thus strengthening our results.

In conclusion, our study demonstrated that people with OA are significantly associated with an increased risk of the onset of CVD in middle-aged and older participants over an eight-year period. Since some interventions aiming to improve OA symptoms (e.g. increasing physical activity and weight loss reduction) seem to be effective from a cardiological perspective, further studies are needed to better understand if to treat OA is able to decrease CVD risk in these individuals. 


\section{ACKNOWLEDGMENTS}

Conflict of interest: The Authors declare that there is no conflict of interest.

Funding sources: The OAI is a public-private partnership comprised of five contracts(N01-AR-22258; N01-AR-2-2259; N01-AR-2-2260; N01-AR-2-2261; N01-AR-2-2262)funded by the National Institutes of Health, a branch of the Department of Health and Human Services, and conducted by the OAI Study Investigators. Private funding partners include Merck Research Laboratories; Novartis Pharmaceuticals Corporation, GlaxoSmithKline; and Pfizer, Inc. Private sector funding for the OAI is managed by the Foundation for the National Institutes of Health. This manuscript was prepared using an OAI public use data set and does not necessarily reflect the opinions or views of the OAI investigators, the NIH, or the private funding partners.

Role of founding source: The funding sources did not have any role in in study design; in the collection, analysis and interpretation of data; in the writing of the report; and in the decision to submit the article for publication. 


\section{REFERENCES}

1. Vos T, Flaxman AD, Naghavi M, Lozano R, Michaud C et al. (2013) Years lived with disability (YLDs) for 1160 sequelae of 289 diseases and injuries 1990-2010: a systematic analysis for the Global Burden of Disease Study 2010. Lancet 380:2163-96 doi:http://dx.doi.org/10.1016/S0140-6736(12)61729-2

2. Cross M, Smith E, Hoy D, Nolte S, Ackerman I, Fransen M, Bridgett L, Williams S, Guillemin F, Hill CL, Laslett LL, Jones G, Cicuttini F, Osborne R, Vos T, Buchbinder R, Woolf A, March L (2014) The global burden of hip and knee osteoarthritis: estimates from the Global Burden of Disease 2010 study. Annals of the rheumatic diseases 73:1323-30 doi:10.1136/annrheumdis-2013-204763

3. Hiligsmann M, Cooper C, Arden N, Boers M, Branco JC et al. (2013) Health economics in the field of osteoarthritis: an expert's consensus paper from the European Society for Clinical and Economic Aspects of Osteoporosis and Osteoarthritis (ESCEO). Seminars in arthritis and rheumatism 43:303-13 doi:10.1016/j.semarthrit.2013.07.003

4. Hunter DJ, Felson DT (2006) Osteoarthritis. BMJ (Clinical research ed) 332:639-42 doi:10.1136/bmj.332.7542.639

5. Lawrence RC, Helmick CG, Arnett FC, Deyo RA, Felson DT, Giannini EH, Heyse SP, Hirsch R, Hochberg MC, Hunder GG, Liang MH, Pillemer SR, Steen VD, Wolfe F (1998) Estimates of the prevalence of arthritis and selected musculoskeletal disorders in the United States. Arthritis and rheumatism 41:778-99 doi:10.1002/1529-0131(199805)41:5<778::AIDART4>3.0.CO;2-V

6. Veronese N, Stubbs B, Solmi M, Smith TO, Noale M, Cooper C, Maggi S (2016) Association between lower limb osteoarthritis and incidence of depressive symptoms: data from the osteoarthritis initiative (in eng). Age and ageing doi:10.1093/ageing/afw216 
7. Bonnet CS, Walsh DA (2005) Osteoarthritis, angiogenesis and inflammation. Rheumatology 44:7-16 doi:10.1093/rheumatology/keh344

8. Hardingham T (2008) Extracellular matrix and pathogenic mechanisms in osteoarthritis vol 10. doi:10.1007/s11926-008-0006-9

9. Ju H, Dixon IM (1996) Extracellular matrix and cardiovascular diseases. Can J Cardiol 12:1259-67

10. Hall AJ, Stubbs B, Mamas MA, Myint PK, Smith TO (2016) Association between osteoarthritis and cardiovascular disease: Systematic review and meta-analysis. European journal of preventive cardiology 23:938-46 doi:10.1177/2047487315610663

11. Nüesch E, Dieppe P, Reichenbach S, Williams S, Iff S, Jüni P (2011) All cause and disease specific mortality in patients with knee or hip osteoarthritis: population based cohort study. BMJ (Clinical research ed) 342:d1165-d65 doi:10.1136/bmj.d1165

12. Veronese N, Trevisan C, De Rui M, Bolzetta F, Maggi S, Zambon S, Musacchio E, Sartori L, Perissinotto E, Crepaldi G, Manzato E, Sergi G (2016) Association of Osteoarthritis With Increased Risk of Cardiovascular Diseases in the Elderly: Findings From the Progetto Veneto Anziano Study Cohort (in eng). Arthritis \& rheumatology (Hoboken, NJ) 68:1136-44 doi:10.1002/art.39564

13. Rahman MM, Kopec JA, Cibere J, Goldsmith CH, Anis AH (2013) The relationship between osteoarthritis and cardiovascular disease in a population health survey: a cross-sectional study. BMJ open 3:10.1136/bmjopen-2013-002624 doi:10.1136/bmjopen-2013-002624; 10.1136/bmjopen-2013-002624

14. Hoeven TA, Leening MJG, Bindels PJ, Castaño-Betancourt M, van Meurs JB et al. (2014) Disability and not osteoarthritis predicts cardiovascular disease: a prospective populationbased cohort study. Annals of the rheumatic diseases 74:S46-S46 doi:10.1136/annrheumdis2013-204388 
15. Washburn RA, McAuley E, Katula J, Mihalko SL, Boileau RA (1999) The physical activity scale for the elderly (PASE): evidence for validity. Journal of clinical epidemiology 52:64351

16. Katz JN, Chang LC, Sangha O, Fossel AH, Bates DW (1996) Can comorbidity be measured by questionnaire rather than medical record review? Medical care 34:73-84

17. Fernandes GS, Valdes AM (2015) Cardiovascular Disease and Osteoarthritis: Common Pathways and Patient Outcomes. European Journal of Clinical Investigation 45:n/a-n/a doi:10.1111/eci.12413

18. Trelle S, Reichenbach S, Wandel S, Hildebrand P, Tschannen B, Villiger PM, Egger M, Jüni P (2011) Cardiovascular safety of non-steroidal anti-inflammatory drugs: network metaanalysis. BMJ (Clinical research ed) 342:c7086-c86 doi:10.1136/bmj.c7086

19. Sergi G, Veronese N, Fontana L, De Rui M, Bolzetta F, Zambon S, Corti M-C, Baggio G, Toffanello ED, Crepaldi G, Perissinotto E, Manzato E (2015) Pre-frailty and risk of cardiovascular disease in elderly men and women: the pro.v.a. study (in eng). Journal of the American College of Cardiology 65:976-83 doi:10.1016/j.jacc.2014.12.040

20. Rao TP, Kühl M (2010) An updated overview on wnt signaling pathways: A prelude for more vol 106. doi:10.1161/CIRCRESAHA.110.219840

21. Veronese N, Cereda E, Maggi S, Luchini C, Solmi M, Smith T, Denkinger M, Hurley M, Thompson T, Manzato E, Sergi G, Stubbs B (2016) Osteoarthritis and Mortality: A Prospective Cohort Study and Systematic Review with Meta-analysis (in English). Seminars in Arthritis and Rheumatism 46:160-7. doi:10.1016/j.semarthrit.2016.04.002

22. Jonsson H, Helgadottir GP, Aspelund T, Eiriksdottir G, Sigurdsson S, Ingvarsson T, Harris TB, Launer L, Gudnason V (2009) Hand osteoarthritis in older women is associated with carotid and coronary atherosclerosis: the AGES Reykjavik study. Annals of the rheumatic diseases 68:1696-700 doi:10.1136/ard.2008.096289 
23. Watt FE (2015) Hand osteoarthritis, menopause and menopausal hormone therapy. Maturitas 83:13-18 doi:10.1016/j.maturitas.2015.09.007

24. Bay-Jensen AC, Slagboom E, Chen-An P, Alexandersen P, Qvist P, Christiansen C, Meulenbelt I, Karsdal Ma (2013) Role of hormones in cartilage and joint metabolism: understanding an unhealthy metabolic phenotype in osteoarthritis. Menopause (New York, NY) 20:578-86 doi:10.1097/GME.0b013e3182745993

25. Kluzek S, Sanchez-Santos MT, Leyland KM, Judge A, Spector TD, Hart D, Cooper C, Newton J, Arden NK (2015) Painful knee but not hand osteoarthritis is an independent predictor of mortality over 23 years follow-up of a population-based cohort of middle-aged women. Annals of the rheumatic diseases:annrheumdis-2015-208056 doi:10.1136/annrheumdis-2015-208056

26. Hoeven TA, Kavousi M, Ikram MA, van Meurs JB, Bindels PJ, Hofman A, Franco OH, Bierma-Zeinstra SM (2015) Markers of atherosclerosis in relation to presence and progression of knee osteoarthritis: a population-based cohort study. Rheumatology (Oxford, England) 54:1692-98 doi:10.1093/rheumatology/kev106

27. Smiley Da, Khalil Ra (2009) Estrogenic compounds, estrogen receptors and vascular cell signaling in the aging blood vessels. Current medicinal chemistry 16:1863-87 doi:10.2174/092986709788186093

28. Poulain-Godefroy O, Le Bacquer O, Plancq P, Lecoeur C, Pattou F, Frühbeck G, Froguel P (2010) Inflammatory role of Toll-like receptors in human and murine adipose tissue. Mediators of inflammation 2010:823486-86 doi:10.1155/2010/823486

29. Akira S, Takeda K (2004) Toll-like receptor signalling. Nature reviews Immunology 4:499511 doi:10.1038/nri1391

30. Pickering TG, Hall JE, Appel LJ, Falkner BE, Graves J, Hill MN, Jones DW, Kurtz T, Sheps SG, Roccella EJ (2005) Recommendations for blood pressure measurement in humans and experimental animals: Part 1: blood pressure measurement in humans: a statement for 
professionals from the Subcommittee of Professional and Public Education of the American Heart Association Cou. Hypertension 45:142-61 doi:10.1161/01.HYP.0000150859.47929.8e

31. Libby P (2006) Inflammation and cardiovascular disease mechanisms. The American journal of clinical nutrition $83: 456 \mathrm{~S}-60 \mathrm{~S}$ 


\section{FIGURES AND TABLES}

Figure 1. Cumulative incidence of cardiovascular disease according to the presence or absence of osteoarthritis (OA) at baseline in the sample as whole.

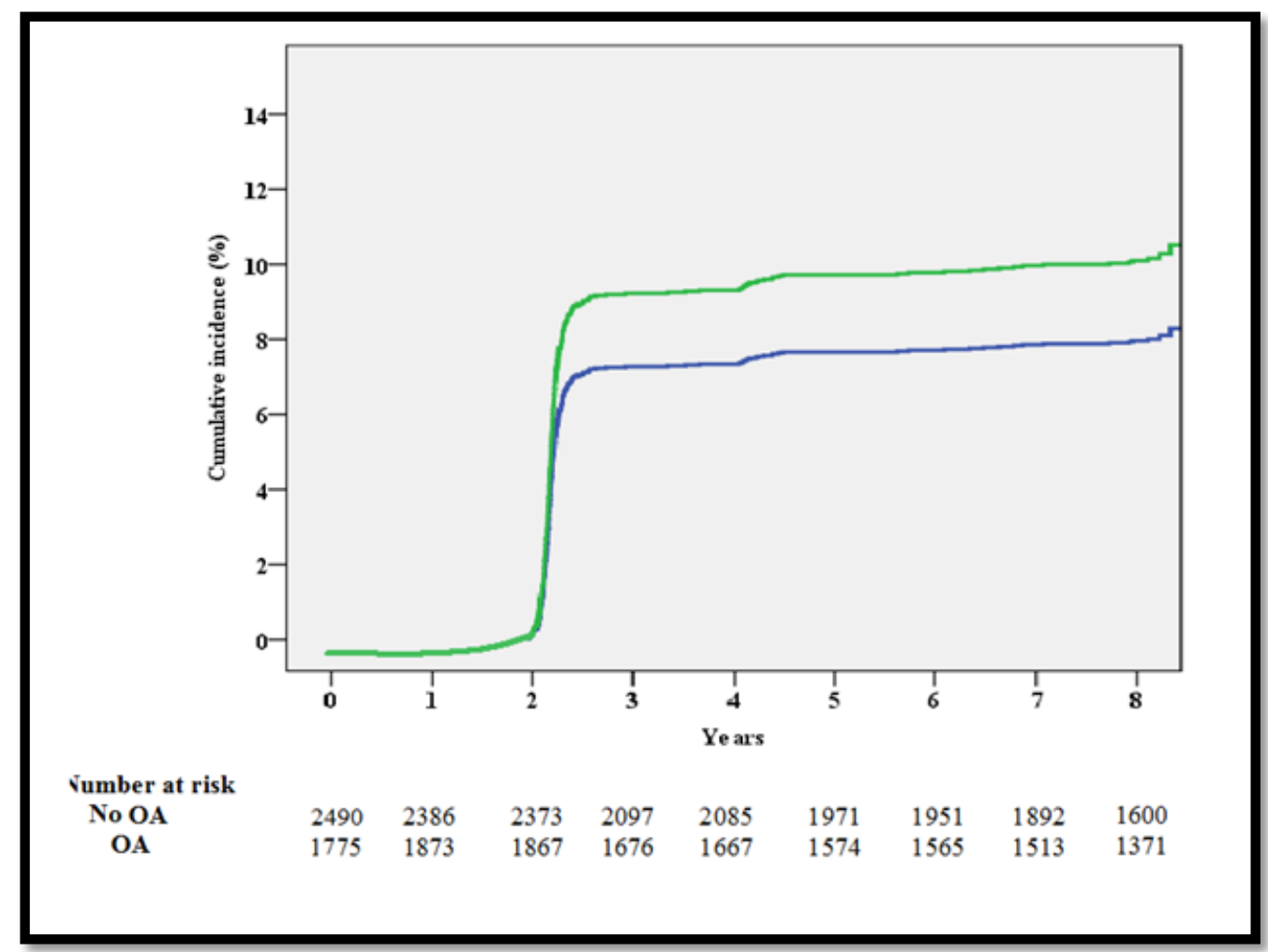

\section{Notes:}

Green line indicates the subjects having OA at baseline, blue line those without.

Values represent the number of subjects with or without OA at risk of cardiovascular disease per year during the follow-up period. 
Table 1. Baseline characteristics classified according to presence or not of osteoarthritis (OA).

\begin{tabular}{|c|c|c|c|c|c|c|}
\hline \multirow[b]{2}{*}{ Variable } & \multicolumn{2}{|c|}{ Whole sample } & \multicolumn{2}{|c|}{ Men } & \multicolumn{2}{|c|}{ Women } \\
\hline & $\begin{array}{c}\text { OA } \\
(\mathbf{n}=1,775) \\
\end{array}$ & $\begin{array}{c}\text { No OA } \\
(n=2,490)\end{array}$ & $\begin{array}{c}\text { OA } \\
(n=626)\end{array}$ & $\begin{array}{c}\text { No OA } \\
(n=1,114)\end{array}$ & $\begin{array}{c}\text { OA } \\
(n=1,149)\end{array}$ & $\begin{array}{c}\text { No OA } \\
(n=1,376)\end{array}$ \\
\hline Age (years) & $62.3(8.6)$ & $59.8(9.1)^{* * * *}$ & $61.7(9.2)$ & $59.6(9.4)^{* * *}$ & $62.6(8.6)$ & $60.0(8.9)^{* * *}$ \\
\hline White race $(n, \%)$ & $1501(84.6)$ & $1937(77.9)^{* * *}$ & $541(86.6)$ & $937(84.2)$ & $960(83.6)$ & $1000(72.7)^{* * *}$ \\
\hline BMI $\left(\mathrm{Kg} / \mathrm{m}^{2}\right)$ & $28.7(4.8)$ & $28.4(4.8)^{* *}$ & $29.1(4.1)$ & $28.6(4.1)^{*}$ & $28.6(5.2)$ & $28.2(5.2)$ \\
\hline PASE (points) & $157.5(81.4)$ & $167.1(83.0)^{* * *}$ & $176.8(88.3)$ & $181.2(88.5)$ & $147.0(75.5)$ & $155.7(76.4)^{* *}$ \\
\hline Smoking (previous/current) & $853(48.6)$ & $1099(44.8)^{*}$ & $335(54.3)$ & $500(45.5)^{* *}$ & $518(45.5)$ & $599(44.2)$ \\
\hline Degree $(n, \%)$ & $586(33.3)$ & $731(29.6)^{* *}$ & $245(39.6)$ & $400(36.3)$ & $341(29.8)$ & $331(24.3)^{* * *}$ \\
\hline Yearly income $(<50,000 \$)$ & $654(36.8)$ & $846(34.0)$ & $161(25.7)$ & $279(25.0)$ & $493(42.9)$ & $567(41.2)$ \\
\hline Medical conditions & & & & & & \\
\hline Diabetes $(n, \%)$ & $125(7.2)$ & $162(6.7)$ & $56(9.1)$ & $70(6.5)^{*}$ & $69(6.1)$ & $92(6.9)$ \\
\hline Cancer $(\mathrm{n}, \%)$ & $87(4.9)$ & $114(4.6)$ & $41(6.5)$ & $64(5.8)$ & $46(4.0)$ & $50(3.6)$ \\
\hline Hypertension (n, \%) & $359(20.2)$ & $217(20.8)$ & $144(23.0)$ & $262(23.5)$ & $215(18.7)$ & $255(18.5)$ \\
\hline Charlson co-morbidity score & $0.32(0.71)$ & $0.26(0.71)^{* * *}$ & $0.32(0.76)$ & $0.26(0.76)$ & $0.33(0.68)$ & $0.26(0.66)^{* * *}$ \\
\hline Use of analgesic drugs (n, \%) & $930(52.5)$ & $735(29.7)^{* * *}$ & $293(47.0)$ & $305(27.6)^{* * * *}$ & $637(55.5)$ & $430(31.4)^{* * *}$ \\
\hline
\end{tabular}

Notes:

P-value: ${ }^{* * *} \mathrm{p}<0.001 ;{ }^{* *}: \mathrm{p}<0.01 ;{ }^{*} . \mathrm{p}<0.05$

Numbers are mean values (and standard deviations) or number (and percentages), as appropriate.

Unless otherwise specified, $p$ values are calculated with an independent Student T-test for continuous and with a chi-square test for categorical variables, respectively.

Abbreviations: BMI: body mass index; PASE: physical activity scale for the elderly. 
Table 2: Associations between presence of osteoarthritis at the baseline and incident cardiovascular diseases.

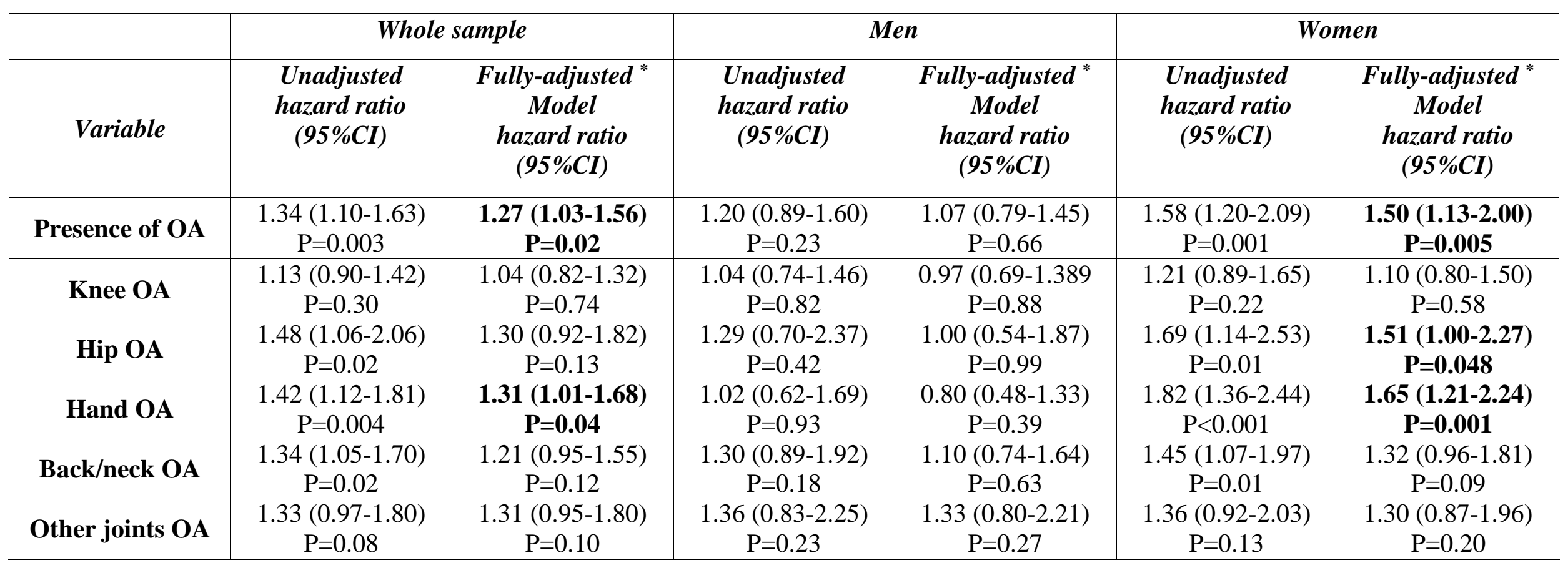

Unless otherwise specified, data are presented as hazard ratios and 95\% confidence intervals.

Bold values are significant results $(\mathrm{p}<0.05)$ after fully-adjustment.

Notes:

${ }^{*}$ Fully-adjusted model included baseline values of: age (as continuous); gender; race (whites vs. others); body mass index (as continuous); education (degree vs. others); smoking habits (current and previous vs. others); yearly income (categorized as $>$ or $<50,000 \$$ and missing data); physical activity scale for the elderly (as continuous); Charlson co-morbidity index (as continuous); presence of hypertension (yes vs. no); use of analgesic drugs (yes vs. no).

** Those without any presence of osteoarthritis were taken as reference in all analyses. 